\title{
Corrosion Mechanism of Commercial Mg0-C Refractories in Contact with Different Gas Atmospheres
}

\author{
Sune JANSSON, ${ }^{11}$ Voicu BRABIE ${ }^{21}$ and Pär JÖNSSON ${ }^{3)}$ \\ 1) Arvika Gjuteri AB, SE-671 82 Arvika, Sweden. E-mail: sune.jansson@arvikagjuteri.se 2) Dalarna University, SE-781 \\ 88 Borlänge, Sweden. E-mail: vbr@du.se $\quad 3)$ Division of Applied Process Metallurgy, Royal Institute of Technology, SE- \\ 10044 Stockholm, Sweden. E-mail: par@mse.kth.se
}

(Received on February 12, 2008; accepted on March 26, 2008)

\begin{abstract}
Corrosion of $\mathrm{MgO}-\mathrm{C}$ refractories in different gas atmospheres consisting of air, $\mathrm{Ar}$, $\mathrm{CO}$ or $\mathrm{Ar} / \mathrm{CO}$ was studied in laboratory experiments. In total, 103 experiments were carried out in the temperature range 1173 to $1773 \mathrm{~K}$ and for holding times between 2 to $120 \mathrm{~min}$. The reaction rate of the $\mathrm{MgO}-\mathrm{C}$ material was determined from measurements of the weight loss of the samples. The results showed that the refractory weight loss increased with an increased temperature or an increased holding time. The thermodynamic conditions and the experimental results showed that magnesium gas and carbon monoxide gas should form during ladle refining of steel when the refractory material consists of $\mathrm{MgO}-\mathrm{C}$. It was suggested that the reaction rate is directly dependent on the oxygen potential in the ambient atmosphere.
\end{abstract}

KEY WORDS: MgO-C refractory; oxidation-reduction; gas atmosphere; corrosion rate; corrosion mechanism.

\section{Introduction}

Carbon bonded magnesia $(\mathrm{MgO}-\mathrm{C})$ refractory materials are used in the linings of ladles when refining steel. They inhibit slag penetration into the brick structure, as a result of the low wettability of graphite by slag. In addition, they inhibit the brick from thermo-mechanically spalling (surface splitting of the lining) due to graphite's high thermal conductivity and low thermal expansion. Although graphite has a high chemical stability when it is in contact with a molten slag, it is easily oxidized by iron oxide in the slag, ambient gas and $\mathrm{MgO}(\mathrm{MgO}-\mathrm{C}$ reaction). The gas-phase oxidation is caused by oxygen and carbon dioxide in the ambient atmosphere reacting with the carbon in the refractory. This type of oxidation is significant during the heating of ladles as well as the transportation of ladles. However, several studies have shown that the formation of a slag layer on the brick surface will decrease the decarburization tendency. ${ }^{1-4)}$

In $\mathrm{MgO}-\mathrm{C}$ brick, carbon is also oxidized by magnesia according to the following reaction:

$$
\mathrm{MgO}_{(\mathrm{s})}+\mathrm{C}_{(\mathrm{s})}=\mathrm{Mg}_{(\mathrm{g})}+\mathrm{CO}_{(\mathrm{g})}
$$

Equation (1) can be obtained by combining the following two reactions:

$$
\begin{gathered}
\mathrm{Mg}(\mathrm{g})+1 / 2 \mathrm{O}_{2}(\mathrm{~g})=\mathrm{MgO} \\
\mathrm{C}+1 / 2 \mathrm{O}_{2}=\mathrm{CO} \ldots \ldots \ldots
\end{gathered}
$$

The free energy changes for Eqs. (1)-(3) in the temperature range $298-2000 \mathrm{~K}$ can be calculated as follows using standard reference tables ${ }^{5)}$ :

$$
\begin{gathered}
\Delta G_{1}=-615600+1118.23 T-R T \ln P_{\mathrm{Mg}}-R T \ln P_{\mathrm{CO}} \ldots . .(4) \\
\Delta G_{2}=-730000+204 T+R T \ln \frac{1}{p_{\mathrm{Mg}} \cdot p_{\mathrm{O}_{2}}^{1 / 2}} \ldots \ldots .(5) \\
\Delta G_{3}=-114400-85.77 T+R T \ln \frac{p_{\mathrm{CO}}}{p_{\mathrm{O}_{2}}^{1 / 2}} \ldots \ldots \ldots(6)
\end{gathered}
$$

where $p_{\mathrm{Mg}}$ is the partial pressure of $\mathrm{Mg}, p_{\mathrm{O} 2}$ is the partial pressure of $\mathrm{O}_{2}$ and $p_{\mathrm{CO}}$ is the partial pressure of $\mathrm{CO}$.

On the basis of the thermodynamic arguments, the rate of the internal oxide-carbon reactions would be expected to increase with increasing temperature and to decrease at a given temperature with an increase in either $P_{\mathrm{Mg}}$ or $P_{\mathrm{CO}}$ in the ambient atmosphere. ${ }^{1)}$ The influence of the temperature and the partial pressure of $\mathrm{Mg}(\mathrm{g})$ and $\mathrm{CO}(\mathrm{g})$ on reaction (1) is also illustrated in Fig. 1. Magnesium is characterized by a high affinity to oxygen and a very stable oxide. At a temperature of $2120 \mathrm{~K}$ and $1 \mathrm{~atm}$, the $\mathrm{MgO}$ and $\mathrm{CO}$ lines cross each other, as illustrated in the figure. This means that magnesium oxide can be reduced by a reaction with carbon and form magnesium gas according to reaction (1).

Sunayama and Kawahara ${ }^{6}$ have studied decarburization of resin-bonded magnesia-carbon refractory in the temperature range from $1473-1673 \mathrm{~K}$ in $\mathrm{N}_{2}-\mathrm{O}_{2}$ and $\mathrm{Ar}-\mathrm{O}_{2}$ atmospheres. After kinetic analysis, it was suggested that the 


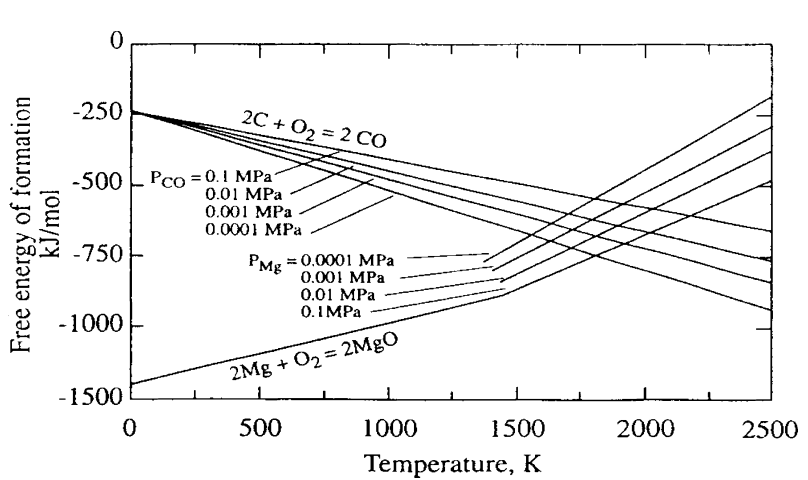

Fig. 1. Equilibrium relation for magnesium and carbon monoxide. $^{4)}$

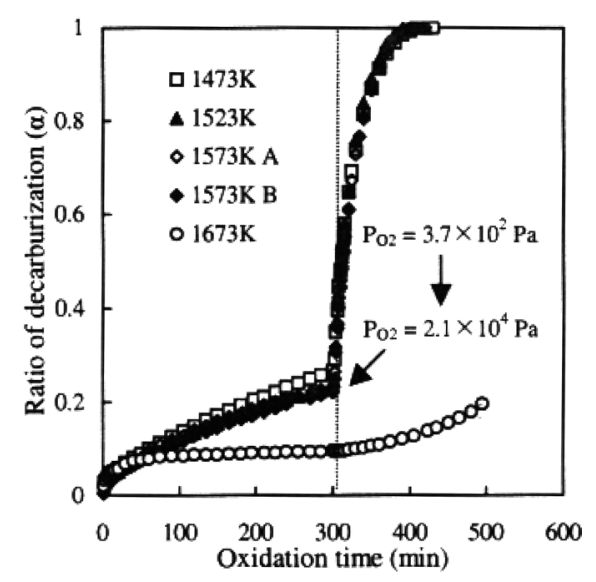

Fig. 2. Effect of temperature on the oxidation rate in atmosphere with oxygen partial pressure of $3.7 \times 10^{2} \mathrm{~Pa}$ and $2.1 \times 10^{4} \mathrm{~Pa}^{6}{ }^{6}$

overall oxidation process was controlled by the diffusion of oxygen through the decarburized layer. The confirmation of a dense layer formation on the surface of the sample was achieved by the observation of the cross section of the sample after the oxidation test. It is interesting to note that the authors observed an increase in the oxidation rate when the oxygen potential pressure changes from $3.7 \times 10^{2} \mathrm{~Pa}$ to $2.1 \times 10^{4} \mathrm{~Pa}$, as illustrated in Fig. 2. Furthermore, they found that when the temperature reached $1673 \mathrm{~K}$ the oxidation rate became constant.

Komarek et al. ${ }^{7)}$ studied the reaction between magnesia and graphite in vacuum by measuring the amount of carbon monoxide formed during the reaction. They observed that the reaction was phase-boundary controlled. Furthermore, that a linear time law was obtained for all experiments. They considered that the reaction proceeds over the gas phase by dissociation of the oxide into atomic oxygen followed by the rate controlling step, desorption of $\mathrm{CO}$ from the graphite surface. Gulyanitzkii and Chizhikov ${ }^{8)}$ made similar experiments as Komarek et $a l^{7)}$ by determining the corrosion by measuring the weight loss. They concluded that the rate controlling step was the gas phase reaction involving carbon oxides.

Fruehan et al. ${ }^{9)}$ studied the rate of reduction of $\mathrm{MgO}$ by carbon in $\mathrm{Ar}, \mathrm{He}$ and $\mathrm{CO}$ atmospheres at 1748-1873 K. The amount of carbon remaining in the refractory was determined after cooling of the samples. In addition, the weight loss was determined for all samples. They noticed that the weight loss in general showed a linear behavior

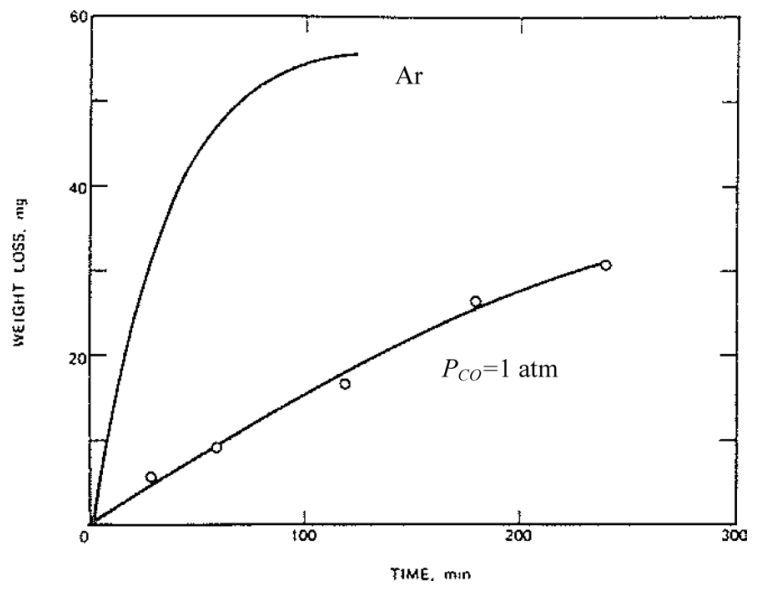

Fig. 3. The rate of weight loss for an $\mathrm{MgO}-\mathrm{C}$ sample in $\mathrm{Ar}$ and $\mathrm{CO}$ at $1823 \mathrm{~K}^{9}{ }^{9}$

with time and that the reaction rates (determined using Eq. (1)) corresponded well with the weight loss. According to Fruehan et al. $^{9)}$ the mass transfer of the dissolution of solid phase into gas phase can be calculated as follows:

$$
\ln \left(1-\frac{w_{0}-w_{t}}{w_{0}}\right)=-k \cdot t
$$

where $w_{0}$ is the weight of the sample before the test, $w_{t}$ is the weight of the sample after time $t$.

Seiltveit ${ }^{2)}$ has also investigated the loss of weight of the refractory material in an inert gas atmosphere at temperatures greater than $1723 \mathrm{~K}$. The results show that the loss of weight depends on the reaction between carbon and solid or liquid oxide phases, and the main components of the refractory material.

Leonard et al. ${ }^{1)}$ performed laboratory experiments with carbon-bearing BOF refractory at temperatures between 1473 and $1873 \mathrm{~K}$ and in air, He and $\mathrm{CO}$ atmospheres. They found that the reaction rates increased with increased temperature and decreased with an increased $p_{\mathrm{MgO}}$ and/or $p_{\mathrm{CO}}$ at a constant temperature. Also, according to Leonard et al. ${ }^{1)}$ in the interior of the sample reaction (1) proceeds to the right and $\mathrm{Mg}(\mathrm{g})$ diffuses towards the free surface of the sample encounters a much higher oxygen potential and it is oxidized to $\mathrm{MgO}$ which condenses as a dense layer. The reaction rate is reduced substantially. The process within the sample was no longer occurring in an open system. The reactions continue, but probably by counter diffusion of $\mathrm{CO}$ and oxygen across the dense layer.

In general, it can be concluded from previous research that an inert atmosphere is beneficial for decreasing the corrosion of carbon-bonded magnesia refractory. As illustrated in Fig. 3, the loss of weight occurs during a shorter time and with an increased rate than in $\mathrm{CO}$ atmosphere if the pressure is 1 atm. ${ }^{9)}$

In the present work, the focus is on the oxidation rate of commercial carbon-bonded magnesia refractory for different temperatures, holding times and atmospheres (air, Ar, $\mathrm{CO}$ or $\mathrm{Ar} / \mathrm{CO}$ ). In the first part of the paper, the experimental procedure is described. Thereafter, the experimental results are presented and discussed. 
Table 1. Test parameters.

\begin{tabular}{|c|c|c|}
\hline Temperatures, $\mathbf{K}$ & Holding time, minutes & Gas atmospheres \\
\hline $1173 ; 1373 ; 1573 ; 1773$ & $2-120$ & $\begin{array}{c}\text { Air; Argon; Carbon monoxide; } \\
\text { Mix of Ar and CO }(25 / 75 ; 50 / 50 ; 75 / 25)\end{array}$ \\
\hline
\end{tabular}

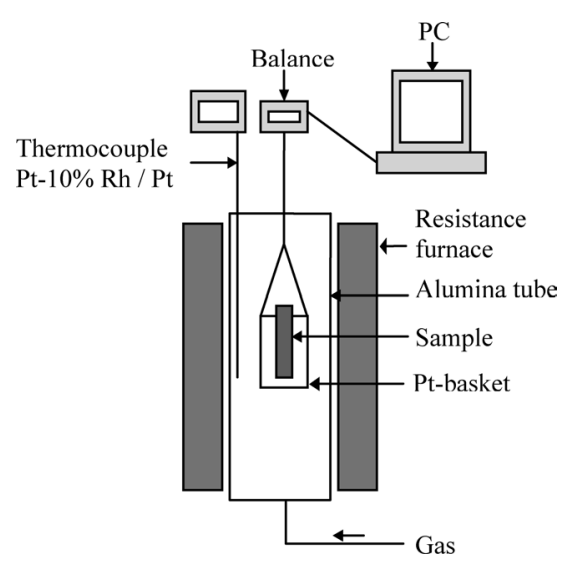

Fig. 4. Experimental apparatus.

\section{Experimental Work}

The reaction between carbon-bonded magnesia refractory and gas atmospheres was studied using the experimental set-up shown in Fig. 4. An alumina tube is placed inside the furnace, through which the gas can be supplied during the experiments. A Pt-basket containing the refractory sample which is to be studied was placed in the alumina tube. The refractory test samples were cut from a commercial $\mathrm{MgO}-\mathrm{C}$ brick with the following chemical composition: $\mathrm{MgO}=96.8 \mathrm{wt} \% ; \mathrm{CaO}=1.8 \mathrm{wt} \% ; \mathrm{SiO}_{2}=0.6 \mathrm{wt} \% ; \mathrm{Fe}_{2} \mathrm{O}_{3}=$ $0.3 \mathrm{wt} \%$ and carbon retained $=5.5 \mathrm{wt} \%$. The samples had a density of $3.1 \mathrm{~g} / \mathrm{cm}^{3}$ and a porosity of $5 \%$. The test samples had a diameter of $13 \mathrm{~mm}$ and a length of $20 \mathrm{~mm}$.

Initially, the samples were preheated to $773 \mathrm{~K}$ before testing so that the volatile elements in the samples would not disturb the results. The preheating was carried out in an inert argon atmosphere.

When the furnace reached the desired temperature for the specific experiment, the samples were placed in the Ptbasket. The different holding times for the experiments were $2-120 \mathrm{~min}$ and the temperatures were $1173-1773 \mathrm{~K}$. In addition, experiments were carried out using gas atmospheres consisting of air, Ar, $\mathrm{CO}$ or different mixtures of $\mathrm{Ar}$ and $\mathrm{CO}$. The test parameters used in the experiments are summarized in Table $\mathbf{1 .}$

During the tests, the gas being studied was flushed through the furnace at a rate of $2 \mathrm{~L} / \mathrm{min}$. The argon gas and the carbon monoxide gas were cleaned by letting the gas pass through a gas-cleaning system consisting of a column of silica gel, a column of magnesium per chlorate, a column of ascarite, and a column of magnesium chips at $773 \mathrm{~K}$. The air was cleaned using a particle filter and a moisture trap.

After the experiments, the refractory samples were removed from the furnace. The weight of the samples was measured and the weight loss was determined as:

$$
\Delta W=W_{0}-W_{t}
$$

where $W_{0}$ is the weight before the tests and $W_{t}$ is the weight after time $t$. The estimated error of the balance was $\pm 1 \mathrm{mg}$.

Cross sections of the oxidized samples were examined by using an optical microscope (Leica Quantimet 500) and a Scanning Electron Microscope, SEM (JEOL JSM 820) with an Energy Dispersive X-ray Spectrometer, EDS (Link ISIS 300).

\section{Results and Discussion}

After the experiments, the influence of the gas atmosphere and temperature on the weight loss of the commercial $\mathrm{MgO}-\mathrm{C}$ samples was studied. In addition, the influence of oxide layers, formed on the refractory surface, on the reaction rate of Eq. (1) was studied.

\subsection{The Influence of the Gas Atmosphere on the Weight Loss}

Table 2 and Fig. 5 show the weight loss as a function of time for $\mathrm{MgO}-\mathrm{C}$ samples at $1573 \mathrm{~K}$ and different ambient atmospheres. It is observed that in air the samples lose weight as a result of the oxidation reaction of carbon with oxygen according to reaction (3). The curves of weight loss as a function of time show a parabolic dependence.

Samples tested in argon and CO atmospheres reach a linear rate of weight loss in 45 and $30 \mathrm{~min}$ respectively. The weight loss in air at $1573 \mathrm{~K}$ is 6 times higher than that for samples in Ar and 10.5 times than that in CO. The experimental results and microscopic observations indicate that the magnesia reduction by carbon is dominant for the test conditions when the atmosphere is characterized by a low oxygen potential.

The loss of weight in $\mathrm{Ar}$ at $1773 \mathrm{~K}$ is 1.5 times higher than for the $\mathrm{CO}$ samples, while Fruehan et al. ${ }^{9)}$ reported a difference between $\mathrm{Ar}$ and $\mathrm{CO}$ samples of 5 times. The difference between the values in the present study and their value depends on the experimental conditions and the materials investigated. Fruehan used samples with lower carbon contents $(2.55 \% \mathrm{C})$ and a dimension of $15 \times 15 \times 40 \mathrm{~mm}$. The present samples have a carbon content of $5.5 \%$ and a geometry corresponding to a $13 \mathrm{~mm}$ diameter and a $20 \mathrm{~mm}$ length.

The examinations in an optical microscope showed that the samples were decarburized during the tests. The decarburized zone for the tests at $1573 \mathrm{~K}$ lasting for $30 \mathrm{~min}$ were measured to be $0.26 \mathrm{~mm}$ for the $\mathrm{CO}$ experiment, $0.64 \mathrm{~mm}$ for the argon experiment, and $3.07 \mathrm{~mm}$ for the air experiment, see Fig. 6. The boundary between the decarburized and undecarburized zones was quite clear, as seen in Fig. 6. It was difficult to estimate the decarburized zone for the experiments that were carried out at $1373 \mathrm{~K}$ using Ar and CO, since the separation between the decarburized and un-decarburized zone was indistinct. Thus, for these experiments no values are given in Table 2 . The decarburized zone was measured using an optical microscope equipped with image distance analysis. The experimental error was estimated to be $\pm 0.02 \mathrm{~mm}$. Figure 7 shows the decarburization zones 


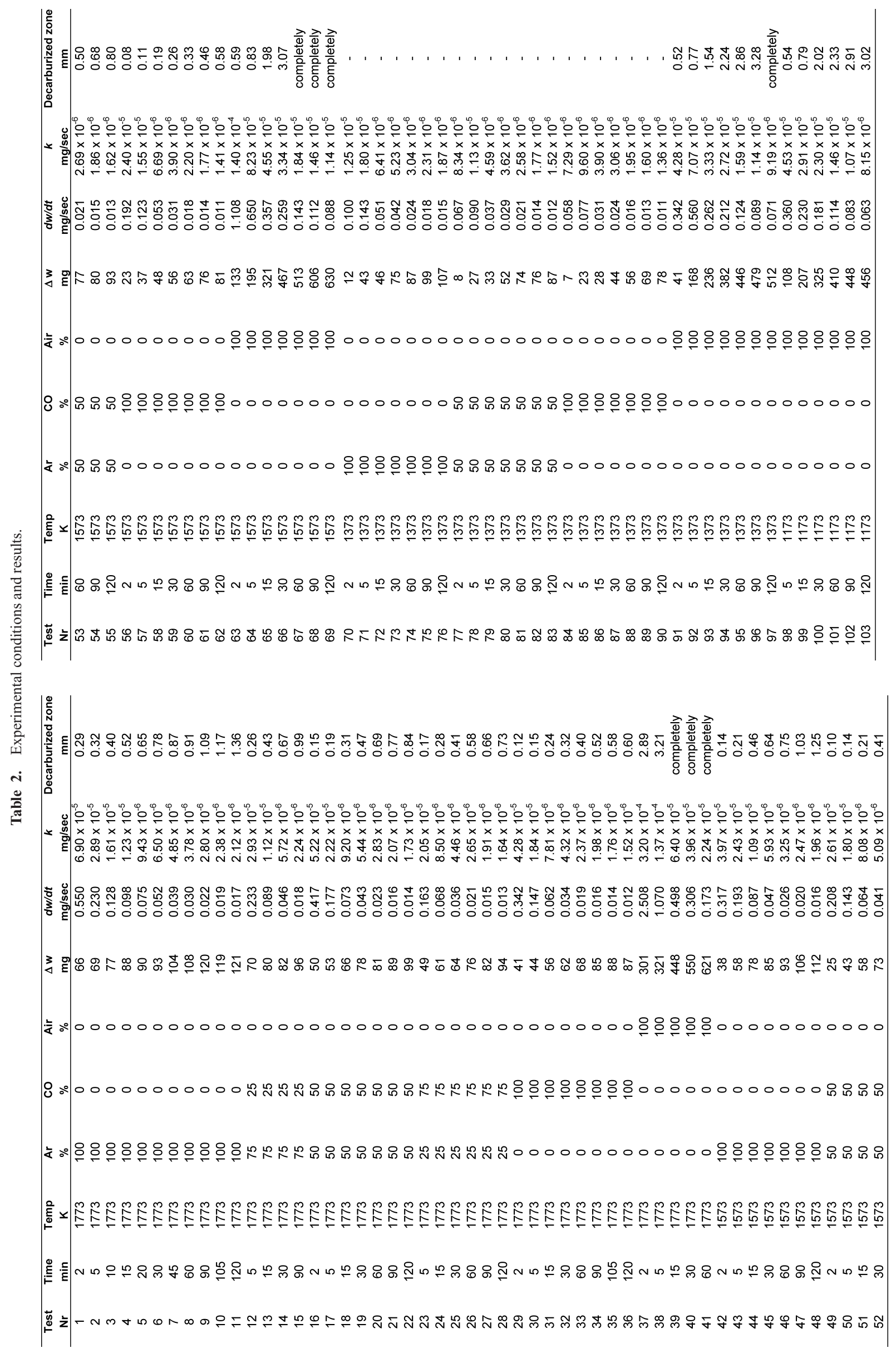


for different reaction times and atmospheres at $1573 \mathrm{~K}$. It was observed that the sample is completely decarburized after $60 \mathrm{~min}$ in an air atmosphere but only $10 \%$ of the sample is decarburized in a $\mathrm{CO}$ atmosphere.

\subsection{The Influence of Temperature on the Weight Loss}

Figure 8 shows the weight loss as a function of temperature and gas atmospheres for experiments, which were conducted for $30 \mathrm{~min}$. The weight loss is seen to increase in a linear manner with an increasing temperature. It is also seen that the weight loss for the $\mathrm{Ar}, \mathrm{Ar}+\mathrm{CO}$ and $\mathrm{CO}$ experiments is considerably lower than that for the air experiments. The reaction rate constant can be calculated using the Arrhenius equation ${ }^{10)}$ :

$$
k=A \cdot \exp \left(-E_{\mathrm{a}} / R T\right)
$$

where $A$ is a pre-exponential term (frequency factor), $E_{\text {a }}$ is the activation energy $(\mathrm{J} / \mathrm{mol}), R$ is the gas constant

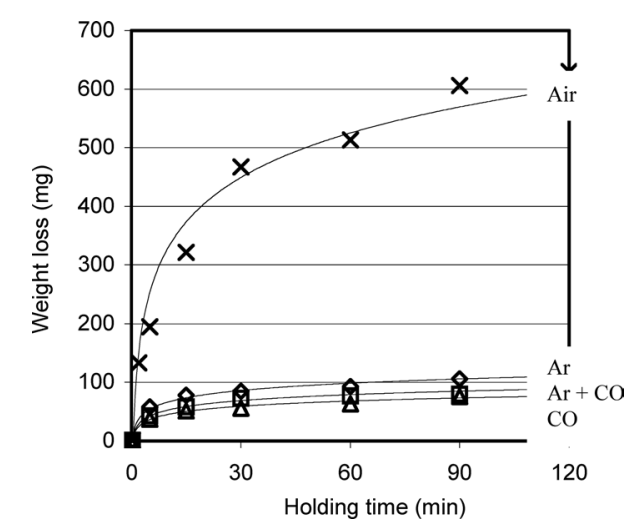

Fig. 5. The weight loss as a function of time for different atmospheres at $1573 \mathrm{~K}$. $\left(8.3145 \mathrm{~J} \mathrm{~mol}^{-1} \mathrm{~K}^{-1}\right)$ and $T$ is the temperature $(\mathrm{K})$. By taking the natural logarithm of both sides of this equation, the following equation is obtained:

$$
\ln k=-\frac{E_{\mathrm{a}}}{R T}+\ln A
$$

In Fig. 9, the logarithm of the rate constant is plotted versus $1 / T$ in a so called "Arrhenius plot". ${ }^{10}$ ) The figure is based on the data in Table 2 . The activation energy was determined from the slopes of the lines in the figure. The results were the following: $101.9 \mathrm{~kJ} / \mathrm{mol}$ for the tests in air, $87.3 \mathrm{~kJ} / \mathrm{mol}$ for the tests in $\operatorname{argon}, 93.3 \mathrm{~kJ} / \mathrm{mol}$ for the tests in a $50 \% \mathrm{Ar}+50 \% \mathrm{CO}$ atmosphere and $90.4 \mathrm{~kJ} / \mathrm{mol}$ for the tests in $\mathrm{CO}$. These activation energy values are higher than those of $38-37 \mathrm{~kJ} / \mathrm{mol}$ reported by Sunayama and Kawahara. ${ }^{6)}$ However, they are lower than those reported by Komarek et al. $\left.{ }^{7}\right)(249 \mathrm{~kJ} / \mathrm{mol})$ and Fruehan et al. ${ }^{9)}(657 \mathrm{~kJ} /$ $\mathrm{mol})$. In general, it seems that the large variation of the activation energy data for different experiments depends on the experimental conditions and materials investigated. Komarek $^{7)}$ studied the reaction between oxides and graphite in a vacuum furnace. They used oxide powder thoroughly mixed in the graphite crucible, covered with a layer of graphite powder. In the present study, samples are cut from an industrial brick. Thus, it is assumed that they are not homogeneous as the samples used in earlier laboratory studies by, for example, Komarek et al. ${ }^{7)}$

\subsection{The Influence of Oxide Layers on the Reaction Rate}

The examination of the samples using SEM in combination with EDS showed that a $\mathrm{MgO}$ layer had been formed at the surface of the samples. The layer is considered to be formed by reactions (1) and (2). More specifically, magne-

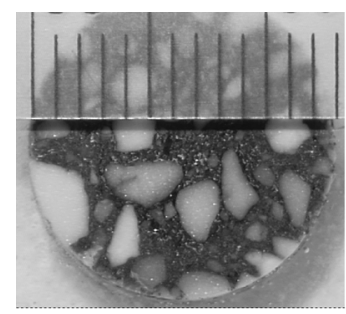

a)

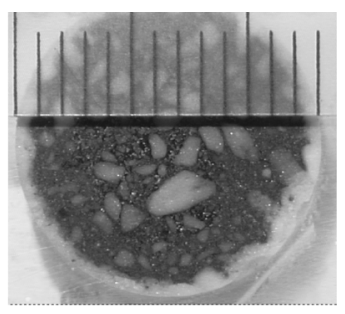

b)

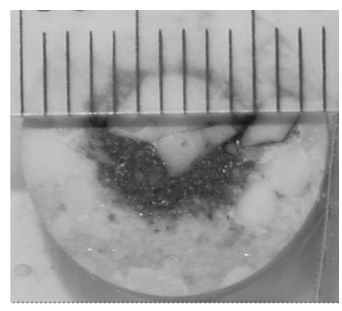

c)

Fig. 6. Pictures of cross-section for different samples at $1573 \mathrm{~K}$ during $30 \mathrm{~min}$, a) $\mathrm{CO}$, b) Ar and c) air. The scales in the pictures indicates $1 \mathrm{~mm}$ between the lines.

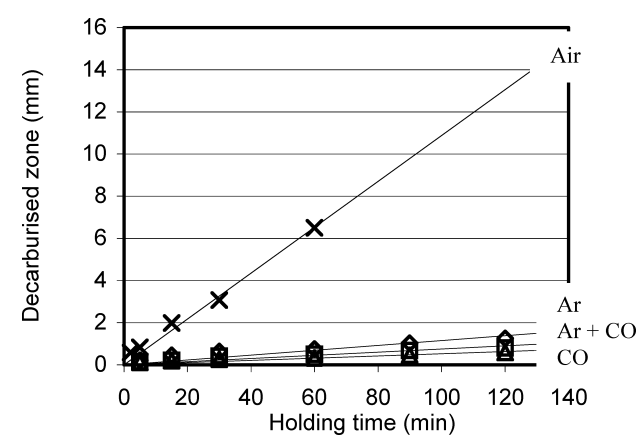

Fig. 7. The effect of holding time on the decarburised zone for different atmospheres at $1573 \mathrm{~K}$.

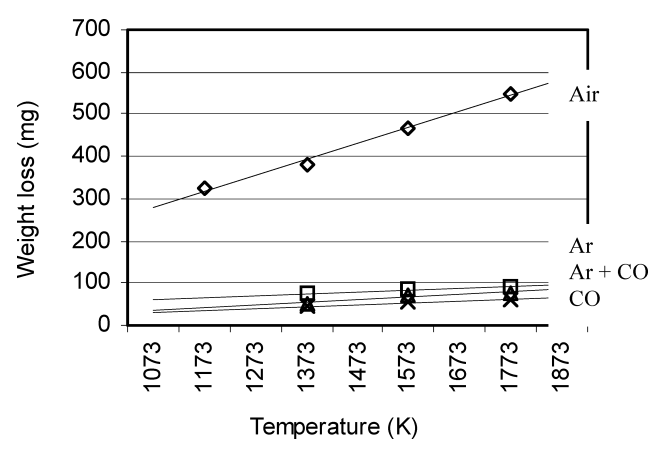

Fig. 8. Weight loss as a function of temperature for different gas atmospheres at $30 \mathrm{~min}$. 
sium vapor formed by the reaction (1) diffuses through the pores in the decarburized layer toward the surface and reacts with oxygen from the atmosphere and forms $\mathrm{MgO}(\mathrm{s})$ according to reaction (2). After formation of the initial scale of $\mathrm{MgO}$, the rate of reaction is controlled by diffusion of magnesium and $\mathrm{CO}$ through the $\mathrm{MgO}$ scale resulting in the parabolic oxidation rate. The dense layer formation will decrease the decarburization of the $\mathrm{MgO}-\mathrm{C}$ lining by retarding the diffusion of carbon and oxygen across the layer.

It is interesting to observe that the decrease of the oxygen potential in the refractory pore atmosphere contributed to a decrease of the carbon oxidation (see Fig. 5 and Ref. 4)) and as a result the oxide layer formation decreased. When an oxide layer has formed at the surface of the sam-

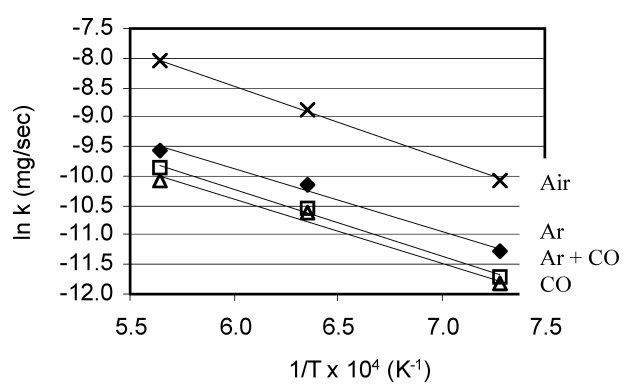

Fig. 9. The temperature's effect on the reaction rate constant for the reduction of $\mathrm{MgO}$ by $\mathrm{C}$ at $2 \mathrm{~min}$. ples the diffusion of reacting elements through the layer decreases and then the carbon oxidation and $\mathrm{MgO}$ reduction decreases. The reduction in the reaction rate was easier to observe in the tests with air atmosphere than in the other tests.

According to Fruehan et al. ${ }^{9)}$ the rates shown in Figs. 3 and 5 are slower in the $\mathrm{CO}$ atmosphere compared to those in the $\mathrm{CO}+\mathrm{Ar}$ or $\mathrm{Ar}$ atmospheres, as the back reaction (see reaction (1)) for oxidation of magnesium by carbon monoxide becomes significant. Thus, the reaction is probably controlled by the oxidation of carbon.

Komarek et al. ${ }^{7)}$ considered that the most probably reaction proceeds by dissociation of $\mathrm{MgO}$. However, Gulyanitzkii et $a l .{ }^{8)}$ concluded that the reduction is primarily due to intermediate reactions in the gas phase involving carbon oxides and not due to the reduction of $\mathrm{MgO}$ vapor or dissociation of $\mathrm{MgO}$ into the $\mathrm{Mg}$ and $\mathrm{O}$ and subsequent reaction with $\mathrm{C}$.

The porosity of the $\mathrm{MgO}$ layer was much less than the original $\mathrm{MgO}$ grains. The chemical composition determination showed that the $\mathrm{MgO}$ layer consisted of approximately the same elements as the original $\mathrm{MgO}$ grains ( $~ 70 \mathrm{wt} \%$ $\mathrm{Mg}, 28 \mathrm{wt} \% \mathrm{O}, 1 \mathrm{wt} \% \mathrm{Si}$ and $1 \mathrm{wt} \% \mathrm{Ca})$. EDS mapping images of the examined layers are shown in Figs. 10 and $\mathbf{1 1 .}$ Figure 10 shows that the original pores that initially were impregnated with carbon have now been decarburized. The

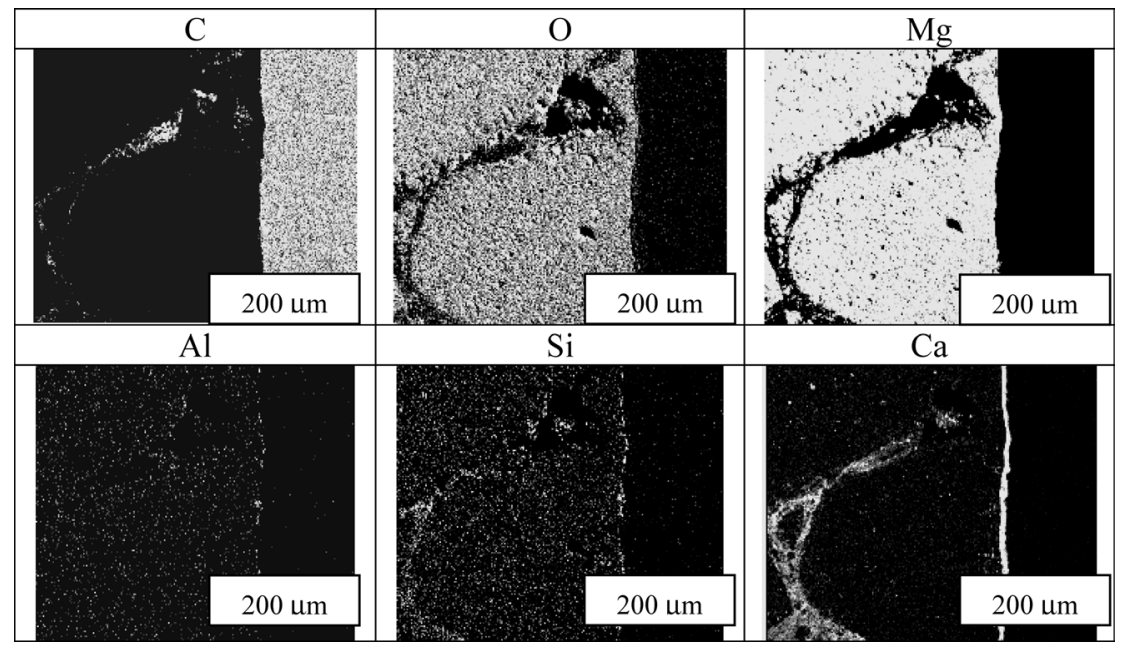

Fig. 10. X-ray mapping images of cross-section of a sample that has been in argon atmosphere at $1773 \mathrm{~K}$ for $105 \mathrm{~min}$.

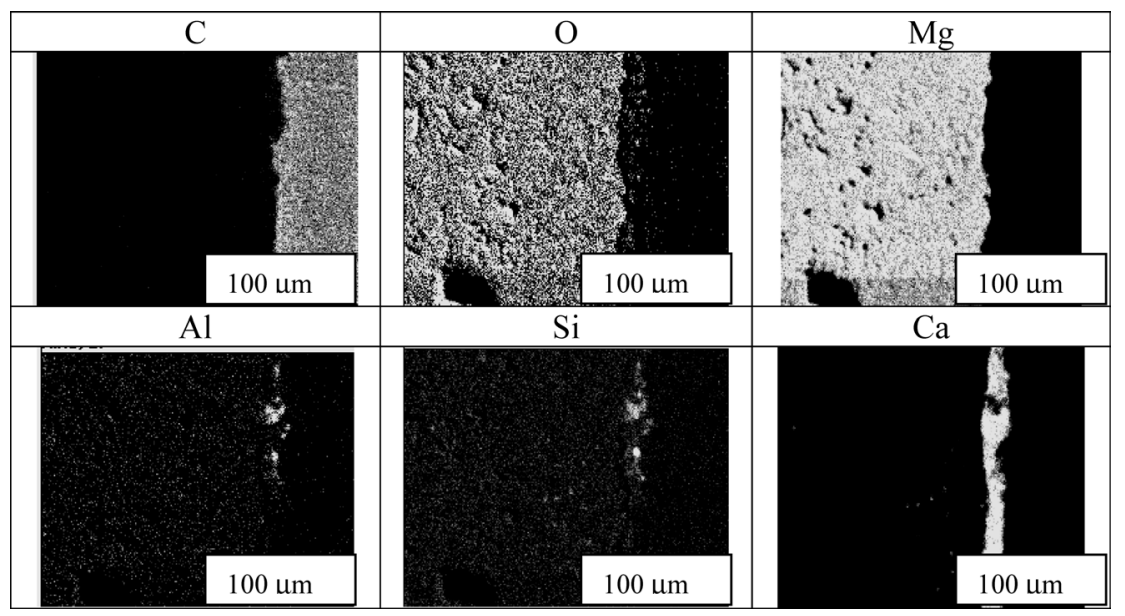

Fig. 11. X-ray mapping images of cross-section of a sample that has been in argon atmosphere at $1773 \mathrm{~K}$ for $105 \mathrm{~min}$. 
amount of carbon remaining in the pores is small. Instead, calcium, silicon and aluminium were found in the pores and they probably derive from impurities in the bulk. From the mapping images shown in Fig. 11 it is clear that the $\mathrm{MgO}$ layer on the surface of the sample has less porosity than the original $\mathrm{MgO}$ grains, which can be observed at the side of the $\mathrm{MgO}$ layer. It is not clear whether the $\mathrm{MgO}$ layer has recently been formed as a secondary layer or if it is magnesium gas that has been reoxidised in pores and cracks and in that way formed a less porous layer. The $\mathrm{MgO}$ layer has also been formed between the original $\mathrm{MgO}$ grains and thereby filled up cavities present between the grains. The $\mathrm{MgO}$ layer had a thickness of $50-100 \mu \mathrm{m}$ and was found around all the test samples.

A $\mathrm{CaO}$ layer was also found on the outside of the $\mathrm{MgO}$ layer. Its thickness was $5-10 \mu \mathrm{m}$ and it was also present around all the test samples. This layer has probably been formed from calcium gas originating from impurities inside the refractory material and which has been oxidised at the surface. Both the $\mathrm{MgO}$ and $\mathrm{CaO}$ layers make the reaction rate inside the refractory material decrease, since the reaction's products must diffuse through the layers in order for a further reaction to proceed. The formation of these layers is most likely dependent on the temperature, because they were not observed at the lower experimental temperatures.

In the $\mathrm{CaO}$ layer, small amounts of aluminium and silicon were found. They probably have their origin from impurities inside the refractory material. The SEM/EDS examinations of the cross-sections of the samples also showed some metallic phases inside the refractory material. The chemical composition of these metallic phases was analysed using dot analysis. A working distance of $25 \mathrm{~mm}$ and an acceleration voltage of $20 \mathrm{kV}$ were used in all EDS determinations. In addition, the SEM/EDS was calibrated using a cobalt standard. The metallic phases were spread out over the whole cross-section of the sample and they varied in size. The metallic phase could be as little as one single grain between the original $\mathrm{MgO}$ grains or as a phase that has filled out a crack in the original $\mathrm{MgO}$ grain. Figure 12 shows a SEM image of a metallic phase that has filled out cracks in an original $\mathrm{MgO}$ grain. The analysis spectrum from the EDS is shown in Fig. 13. The metallic phase seems to consist of zirconium, calcium and silicon. The other elements that were determined were ignored, since they were only found in very small quantities and probably had their origin from the surrounding matrix. Several dot analyses were carried out and the mean value showed that the metallic phase consists of $70 \mathrm{wt} \%$ zirconium, $28.5 \mathrm{wt} \%$ calcium and $1.5 \mathrm{wt} \%$ silicon. The zirconium, calcium and silicon come from impurities in the refractory material. Other metallic phases that were found were pure iron and aluminium and a mixture of some of these metals. Most of them probably come from oxides that have their origin in impurities in the refractory material that have been reduced by carbon to metallic phases.

The metallic phase of aluminium can react with carbon monoxide and form aluminium oxide and carbon. Yamaguchi et al. ${ }^{11)}$ described how aluminum can work as an antioxidant to suppress carbon oxidation as in the following reaction:

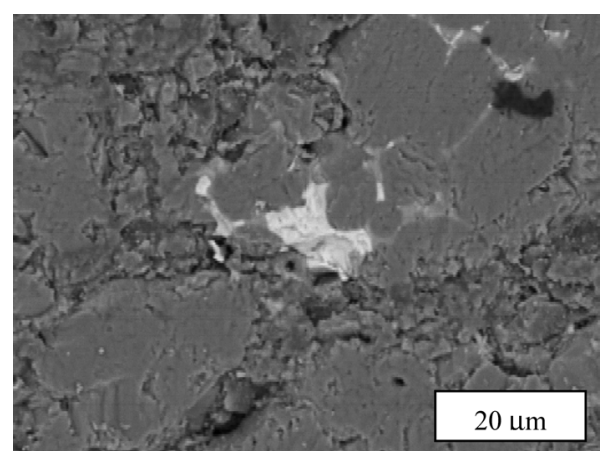

Fig. 12. SEM backscatter image in the metallic phase that has been in air atmosphere at $1573 \mathrm{~K}$ during $15 \mathrm{~min}$.

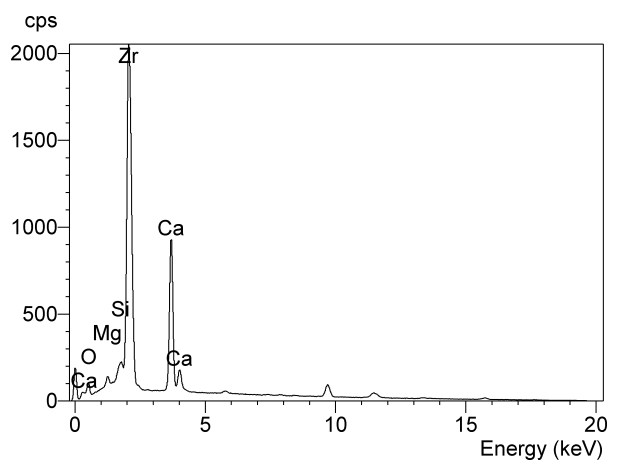

Fig. 13. EDS analysis spectrum for a metallic phase that has been in air atmosphere at $1573 \mathrm{~K}$ for $15 \mathrm{~min}$.

$$
2 \mathrm{Al}+3 \mathrm{CO}_{(\mathrm{g})}=\mathrm{Al}_{2} \mathrm{O}_{3(\mathrm{~s})}+2 \mathrm{C}_{(\mathrm{s})}
$$

$\mathrm{Al}$ reacts with $\mathrm{CO}_{(\mathrm{g})}$ to form $\mathrm{Al}_{2} \mathrm{O}_{3(\mathrm{~s})}$ and $\mathrm{C}_{(\mathrm{s})}$ and compensates the decrease of carbon. At the same time, the formed $\mathrm{Al}_{2} \mathrm{O}_{3}$ plays a role in the densification and the formation of a protective layer near the surface of the refractories, which suppresses the diffusion of oxygen into the refractories.

\section{Conclusions}

The rates of reactions of commercial $\mathrm{MgO}-\mathrm{C}$ refractories in different atmospheres consisting of air, $\mathrm{Ar}, \mathrm{CO}$ or $\mathrm{Ar} / \mathrm{CO}$ were studied using laboratory experiments. In total, 103 experiments were carried out at temperatures ranging from 1173 to $1773 \mathrm{~K}$ and at holding times ranging from 2 to $120 \mathrm{~min}$. The reaction rate of the $\mathrm{MgO}-\mathrm{C}$ material was determined by measuring the weight loss of the samples. The internal oxidation-reduction is assumed to increase with increasing temperature and to decrease at a certain temperature with either an increase in the partial pressure of magnesium or carbon monoxide. In the beginning of the oxidation-reduction, the reaction rate is controlled by the diffusion of reactants through the gas boundary layer near the surface of the samples. Furthermore, when an oxide layer is formed, the diffusion through the oxide layer determines the reaction rate.

The primary findings of the investigations are summarized below.

(1) The weight loss in an air atmosphere was up to 6 times greater than in an $\mathrm{Ar}$ atmosphere and 10.5 times greater than in a $\mathrm{CO}$ atmosphere. Other investigations have 
shown a greater difference in weight loss between Ar and $\mathrm{CO}$ than the present results. This is due to differences in the experimental conditions and materials investigated.

(2) The results show that the weight loss from the samples principally comes from the loss of carbon and oxygen.

(3) The samples are completely decarburized after a 60 min holding time in an air atmosphere, but only $10 \%$ is decarburized after a $60 \mathrm{~min}$ holding time in a $\mathrm{CO}$ atmosphere.

(4) The activation energy was found to be $87-101 \mathrm{~kJ} /$ mol. These data are lower than those reported by Fruehan et al. $(675 \mathrm{~kJ} / \mathrm{mol})$ and Komarek et al. $(249 \mathrm{~kJ} / \mathrm{mol})$, but slightly higher than those reported by Sunayama et al. $(37-38 \mathrm{~kJ} / \mathrm{mol})$.

(5) If the diffusing rate decreases in the system, the reaction rate decreases consequentially.

(6) The carbon loss and the reduction of oxides that occurs as a result of the internal reactions at higher temperatures lead to the formation of cavities between the refractory grains and the remaining carbon structure. These cavities imply that the total porosity in the refractory increases, which can lead to a reduction in the mechanical strength and, in combination with other mechanisms, lead to disintegration of the refractory material. Overall, the results indicate that decarburization and deterioration of the refractory materials occur during the heating up of the ladles in the steelmaking processes.
(7) The layer that forms on the surface of the samples consists of oxygen, magnesium, aluminum, silicon and calcium.

\section{Acknowledgment}

The authors wish to thank The Swedish Steel Producers' Association (Jernkontoret) and The State Energy Authority (STEM) for the financial support of this project.

\section{REFERENCES}

1) R. J. Leonard and R. H. Herron: J. Am. Ceram. Soc., 55(1972), 1.

2) A. Seltveit: Ildfaste Materialer, Tapir Forlag, Norway, (1992), 209.

3) S. C. Carniglia: Ceram. Bull., 52 (1973), 160

4) V. Brabie: Steel Res., 2 (1997), 54.

5) T. A. Engh: Principle of Metal Refining, Oxford University Press, Inc, New York, (1992), 1.

6) H. Sunayama and M. Kawahara: Proc. of 2004 Joint Int. Meet. on High Temp. Corrosion and Mat. Chem., The Electrochemical Society of Japan, Tokyo, (2004).

7) K. L. Komarek, A. Coucoulas and N. Klinger: J. Electrochem. Soc., 7 (1963), 783

8) B. S. Gulyanitzkii and D. M. Chizhikov: Isv. Akad. Nauk., 11 (1955), 13.

9) R. J. Fruehan and L. J. Martonik: Metall. Trans. B, 7B (1976), 537.

10) R. H. Petrucci and W. S. Harwood: General Chemistry, 6th ed., Macmillan Publishing Company, New York, (1993), 535.

11) A. Yamaguchi, Y. Nakano and T. Wang: Can. Metall. Q., 39 (2000), 381 . 